\title{
RETRACTED ARTICLE: Is the Shroud of Turin in relation to the Old Jerusalem historical earthquake?
}

\author{
A. Carpinteri · G. Lacidogna $\cdot$ O. Borla
}

Received: 6 June 2013/Accepted: 15 December 2013/Published online: 11 February 2014

(C) Springer Science+Business Media Dordrecht 2014

This article has been withdrawn by the Publisher and the Society in agreement with the Editor-in-Chief due to conflict of interest reasons. In a commitment to scientific integrity we decided to withdraw the article as the editorial process had been compromised.

A. Carpinteri $(\bowtie) \cdot$ G. Lacidogna $\cdot$ O. Borla

Department of Structural, Geotechnical and Building

Engineering, Politecnico di Torino, Corso Duca degli

Abruzzi 24, 10129 Turin, Italy

e-mail: alberto.carpinteri@polito.it

G. Lacidogna

e-mail: giuseppe.lacidogna@polito.it

O. Borla

e-mail: oscar.borla@polito.it 